\title{
Effect of Ginger on Testicular Tissue of Adult Male Albino Rats Treated with monosodium Glutamate (light and electron microscopic studies)
}

\author{
Hassan S El Wakeel MBB, Ch*1, Moustafa A Al-Gizawy MD², Abd El Razek A Meselhy MD ${ }^{1}$
}

\begin{abstract}
* Corresponding Author: Hassan S El Wakeel doctor7asan85@gmail.com Received for publication March 21, 2020; accepted October 23, 2020; published online October 23, 2020.
\end{abstract}

Copyright 2020 The Authors published by Al-Azhar University, Faculty of Medicine, Cairo, Egypt. All rights reserved. This an openaccess article distributed under the legal terms, where it is permissible to download and share the work provided it is properly cited. The work cannot be changed in any way or used commercially.

doi: 10.21608/aimj.2020.24902.1164

${ }^{1}$ Department of Anatomy and Embryology (Damietta), Faculty of Medicine, Al-Azhar University.

${ }^{2}$ Department of Anatomy and Embryology (Cairo), Faculty of Medicine, Al-Azhar University.

\begin{abstract}
Background: Monosodium Glutamate (MSG) is one of the most widely used food-additives in commercial foods. The excessive MSG administration may lead to damage to many organs including the testes. Ginger is a medicinal plant, medically used for its antioxidant protection activity and it has a beneficial effect on male reproductive functions.

Aim of the study: This study was performed to find out the effect of MSG on the histology of the seminiferous tubules of adult albino rats and the possibility of recovery without treatment and administration of ginger.

Material and methods: sixty adult male albino rats were divided into three equal main groups, each of which included 20 rats. The control group (C) kept without treatment, treated group (T) which was divided into two subgroups (T1): which were given monosodium glutamate daily orally for 14 days. (T2): which were given monosodium glutamate daily orally and ginger daily orally for 14 days. Recovery group $(\mathrm{R})$ divided into two subgroups, (R1): which subdivided into two subgroups:(R1a) \& (R1b): which were given monosodium glutamate daily for 14 days followed by 6and 13 days without treatment sequentially. (R2): subdivided into two subgroups:(R2a) \& (R2b): which were given monosodium glutamate daily and ginger for 14 days followed by continuous treatment with ginger only for 6 and 13days sequentially.

The light microscopic work was done at the Histology Department, Faculty of Medicine, and the electron microscopic work was done at the Electron Microscopic Unit, Parasitology Regional Center, Al Azhar University during the period from 2018 to 2019. Results: MSG causing an alteration in the histological of testicular tissues. The testicular damage caused by MSG is reversible without treatment or with the administration of Ginger. Conclusion: Ginger has protective effects against MSG on the rat testicular tissue.
\end{abstract}

Keywords: Mono Sodium Glutamate (MSG); Ginger; Albino rats; testes; seminiferous tubules.

Authorship: All authors have a substantial contribution to the article.

Disclosure: The authors have no financial interest to declare in relation to the content of this article. The Article Processing Charge was paid for by the authors.

\section{INTRODUCTION}

Glutamate is one of the food enhancer most frequently utilized in fast foods. ${ }^{1}$

MSG has been dangerous to both humans and laboratory animals and has been known to induce signs such as numbness, tiredness, sweat, diarrhea, headache, and dizziness. Many diseases, such as hypertension and cardiac arrhythmias, have continued to cause or exacerbate MSG ingestion. ${ }^{2}$
Higher doses of MSG may cause neurotoxicity and excessive use of MSG might cause hepatic and renal damage. ${ }^{3}$

MSG has a harmful influence on the testis producing oligospermia, which increases irregular sperm shape in

albino rats in a dose-dependent manner. Also, it was implicated in infertility and result in testicular 
hemorrhage, degeneration, and modification of the population of sperm cells and morphology. ${ }^{4}$

Ginger is a knotted plant, dense, beige underground stem (rhizome) used in herbal medicine for millennia to promote digestion and to relieve gastric pain, vomiting, and arthritis. ${ }^{5}$

Zingiber is correlated with a positive impact on male reproductive processes in rats, which is supported by other experiments on the improved sperm numbers, motility, and testosterone rates. Ginger administration also indicates that the rates of plasma testosterone may be greatly raised and stimulate spermatogenesis. ${ }^{6}$

\section{MATERIAL AND METHODS}

This study was done during the period from 2018 to 2019. The light microscopic work was done at the Histology Department, Faculty of Medicine, and the electron microscopic work was done at the Electron Microscopic Unit, Parasitology Regional Center, Al Azhar University.

Animals: In a well-ventilated animal-house 60 adult males of albino-rats weighing 200-230 g are housed in the same laboratory humidity and temperature conditions. The same food and water shall be used by all species.

Chemicals: Preparation of monosodium glutamate:

Monosodium glutamate (MSG) in the form of the white crystalline powder according to (Onyema et al., 2012) ${ }^{7}$ was used in this study, where $4 \mathrm{~g} / \mathrm{kg}$ body weight was dissolved in $2 \mathrm{ml}$ of distilled water.

Preparation of Ginger:

The rhizomes of ginger are sun-dried and ground in a cooker. Weigh the dried powder (1gm) and macerate in $50 \mathrm{ml}$ of distilled water. The ultimate intensity of the extracts would be $20 \mathrm{mg} / \mathrm{ml}$. The extraction is processed in the air-tight vessel and cooled during the test ${ }^{8}$. The ginger was seen at a dosage of $100 \mathrm{mg} / \mathrm{kg}$ body weight in this analysis 9 .

Experimental design: Sixty rats will be divided randomly into three groups; twenty animals each. They will be maintained under the same laboratory conditions. The ginger extract and the monosodium glutamate will be given orally using a gavage tube one time daily for 14 days. ${ }^{10}$

The rates were classified into three main categories:

The first group (Control Group): It was composed of 20 rats which were given $2 \mathrm{ml}$ distilled water and kept without treatment for the same periods as experimental animals for the histological study of the normal tissues of the testis.

The second group (Treated Group): It is divided into two subgroups, each of which included 10 rats:

Subgroup T1: which were given monosodium glutamate daily orally at a dose of $4 \mathrm{~g}$ per $\mathrm{Kg}$ body weight dissolved in $2 \mathrm{ml}$ distilled water for 14 days.

Subgroup T2: which were given monosodium glutamate daily orally at a dose of $4 \mathrm{~g}$ per $\mathrm{Kg}$ body weight dissolved in $2 \mathrm{ml}$ distilled water and given ginger daily orally at a dose of $100 \mathrm{mg}$ per $\mathrm{Kg}$ body weight dissolved in $5 \mathrm{ml}$ distilled water at the same time for 14 days.

The third group (Recovery Group): It is divided into two subgroups, each of which included 10 rats:

Recovery Group (R1): It is subdivided into two subgroups, each of which included 5 rats:
(R1a) and B- (R1b): which were given monosodium glutamate daily orally as a dose of $4 \mathrm{~g}$ per $\mathrm{Kg}$ body weight for 14 days followed by 6 and 13 days without treatment sequentially.

Recovery Group (R2): It included 10 rats and subdivided into two subgroups each of which included 5 rats:

(R2a) and (R2b): which were given monosodium glutamate daily orally at a dose of $4 \mathrm{~g}$ per $\mathrm{Kg}$ body weight and ginger in a dosage of $100 \mathrm{mg} / \mathrm{kg} \mathrm{B}$.W./d for 14 days followed by continuous treatment with ginger only in a dosage of $100 \mathrm{mg} / \mathrm{kg} \mathrm{B.W./d}$ for 6 and 13 days sequentially.

The animals in each subgroup were sacrificed and dissected at the end of each period of this work to obtain the testes, and then the specimens were examined by light and electron microscope.

At the appropriate time, The day after the final dose, rats were sacrificed after being anesthetized with ether. ${ }^{11}$ The testes were carefully dissected, also, each testis was divided into two specimens. One specimen was fixed in aqueous Bouin's solution for preparation of Periodic Acid-Schiff's (PAS) and Hematoxylin \& Eosin (H\&E) stains and the other specimen was fixed in $2.5 \%$ glutaraldehyde for preparation of semithin and ultrathin sections to be examined by a transmission electron microscope.

\section{RESULTS}

Parts of control rat experiments demonstrated the usual histological composition of hematoxylin and eosin stain. The seminiferous tubules tended to be circular or oval covered by a complex stratified epithelium representing various spermatogenesis phases. In between the tubules, interstitial tissue comprising Leydig cells was observed. Seminiferous epithelium displayed two cell groups, Sertoli and spermatogenic cells. Spermatogonia, main spermatocytes, early rounded spermatids, and sperms were the sperm cells that were found in pieces (Fig. 1).

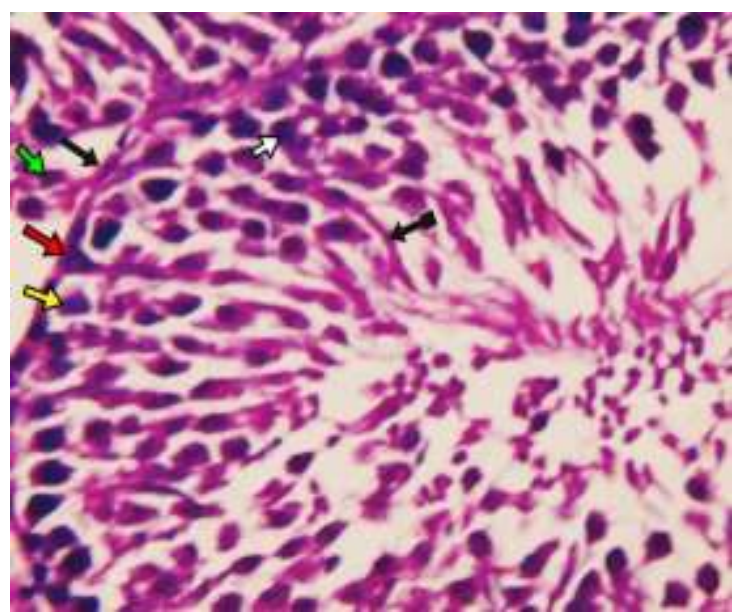

Fig.1: A photomicrograph of a rat testis of control group showing the basement membrane (black arrow), spermatogonia (yellow arrow), primary spermatocytes (white arrow), and sperms in the lumen (black arrow with tail-). Leydig cells (green arrow), Sertoli cells (red arrow) (H\&E. X400). 
The testes in the treated group (T1), showed alterations in their structure as compared with those of the controls. The seminiferous tubules appeared to have irregular outlines with a reduction in the layers of spermatogenic cells. The spaces between the tubules were occupied by acidophilic materials. The basement membrane of some tubules showed partial separation. Other tubules showed discontinuity of the basement membrane (Fig 2).

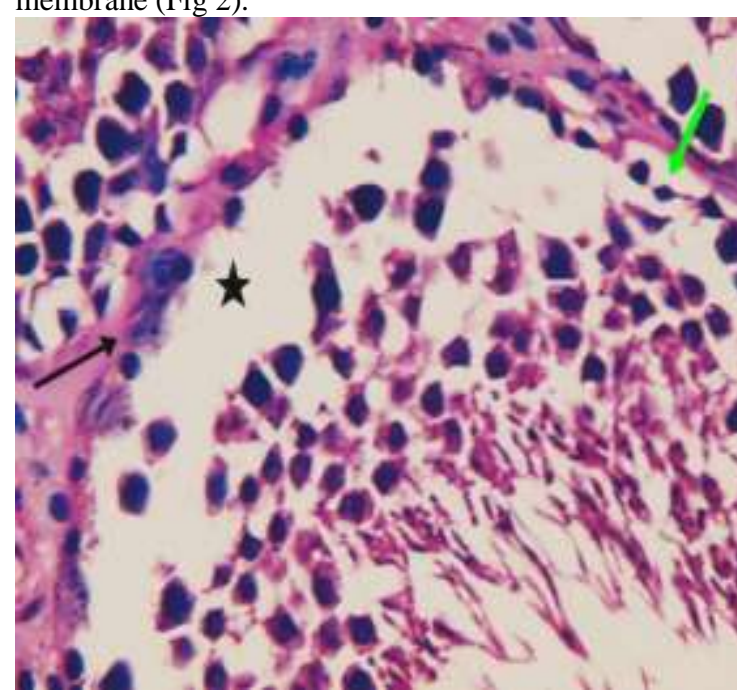

Fig.2: A photomicrograph of a section in the testis of the treated group (T1) showing irregular outlines of the seminiferous tubules (black arrow) with partial separation (black star) of the basement membrane. Some spermatogonia were appeared to contain highly vacuolated cytoplasm (green arrow) (H\&E X400).

The testes in the treated group (T2), showed alterations in their structure as compared with those of the controls. The seminiferous tubules appeared to have irregular outlines with wide spaces between them and reduction in the layers of spermatogenic cells with lost some of the germ cells. Other tubules showed discontinuity and irregularity of the basement membrane (Fig. 3).

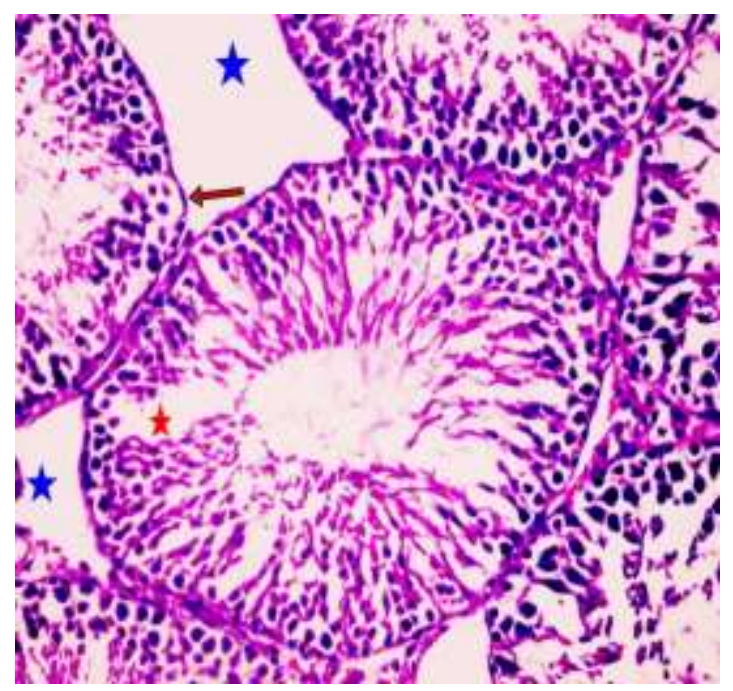

Fig.3: A photomicrograph of a section in the testis of the treated group (T2) showing irregular basement membrane (red arrow), spaces between the seminiferous tubules (blue star) (H\&E X400).
The recovery groups :(R1a) revealed less damage than the (group T1). The tubules were irregular and disorganized, some of the lining cells desquamated in the lumen. The spaces between the tubules were occupied by acidophilic materials with vacuolations. The basement membrane of some tubules showed partial separation (Fig. 4).

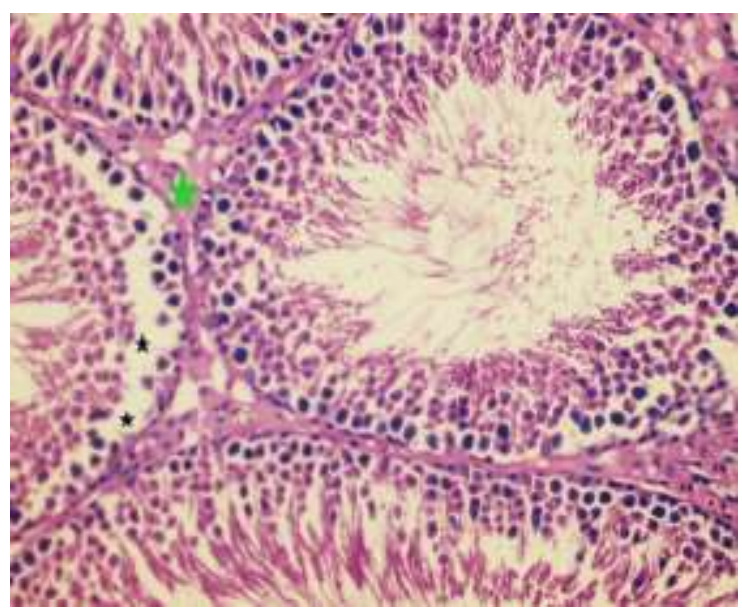

Fig.4: A photomicrograph of a section in the testis of the recovery group (R1a) showing seminiferous tubules with separation between germ cell layers (black stars) and the presence of vacuolated acidophilic material (green star) in the interstitium (H\&E X400).

The testis of the recovery group (R1b) revealed less damage than the previous groups and became more or less similar to the control group (Fig. 5).

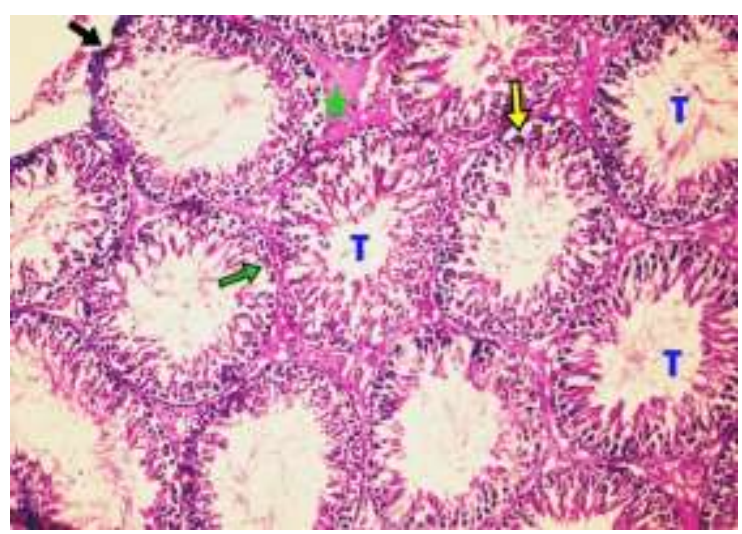

Fig. 5: A photomicrograph of a section in the testis of the recovery group (R1b) showing lost some of the germ cells (green arrow) relatively irregular basement membrane (black arrow) with partial separation of the basement membrane (yellow arrow). Acidophilic vacuolated material (green star) in the interstitium. Other improved tubules (letter T) (H\&E X200).

The testis of the recovery group (R2a) revealed improvement of seminiferous tubules with regular shape but there was a reduction in the layers of some spermatogenic cells with loss of some of the germ cells. The spaces between the tubules were occupied by acidophilic materials (Fig. 6). 


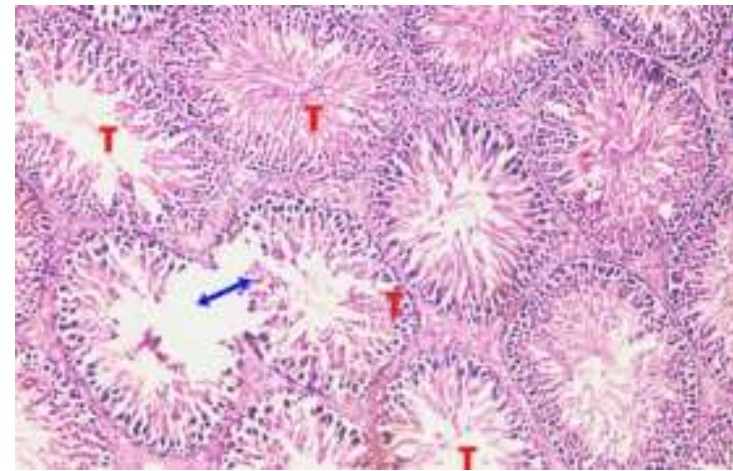

Fig.6: A photomicrograph of a section in the testis of the recovery group (R2a) showing moderately improved seminiferous tubules (letter $\mathrm{T}$ ) with the destruction of the basement membrane (blue arrow) of other tubules (H\&E X200).

Sections in the testis of the recovery group (R2b) revealed improvement of seminiferous tubules with regular shape but very slight changes still present as irregularity of basal lamina of few seminiferous tubules as well as a minimal reduction in the layers of some spermatogenic cells with lost some of the germ cells (Fig. 7).

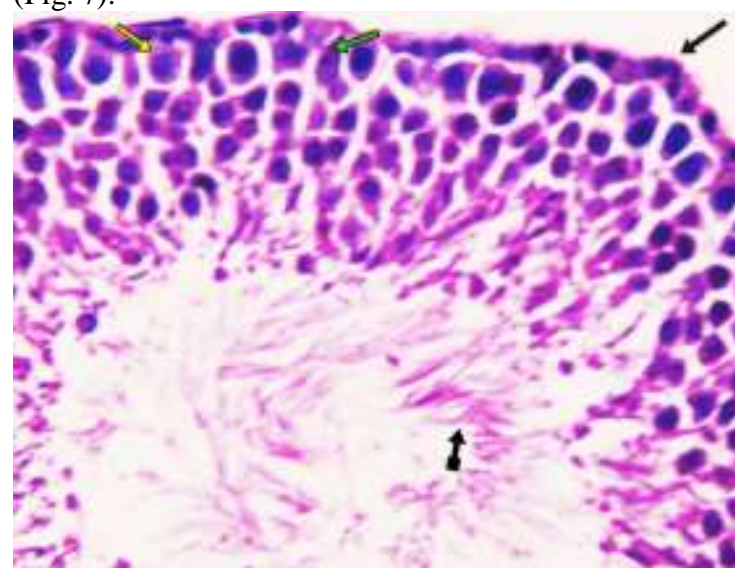

Fig.7: A photomicrograph of a section in the testis of the recovery group (R2b) showing fine irregularity of basement membrane (black arrow) of some seminiferous tubules spermatogonia (yellow arrow), Sertoli cells (green arrow) and sperms (black arrow with tail- $(\mathrm{H} \& \mathrm{E}$ X400).

By (PAS), sections in the testes obtained from control rats showed the normal distribution of PAS materials. PAS-positive reaction was detected in the basement membrane of the tubules which appeared in close relation with germinal epithelium. Also, PAS-positive reaction of acrosomal caps of spermatids (Fig. 8).

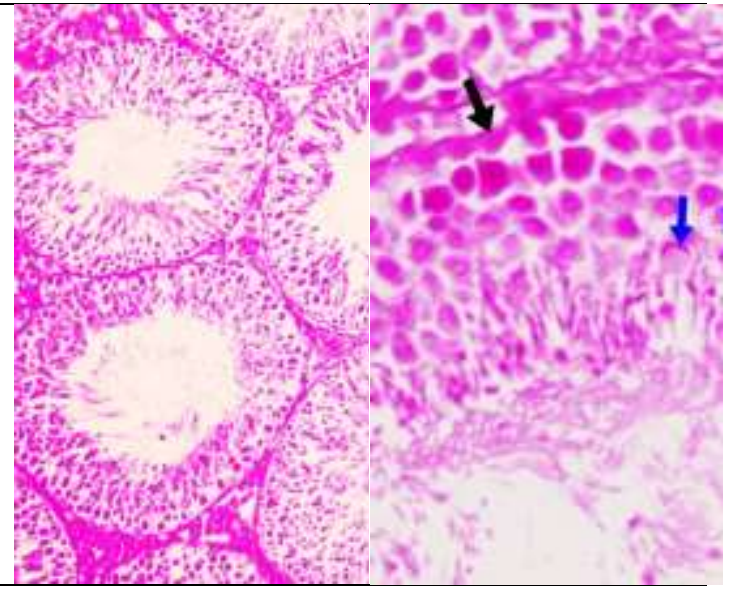

Fig.8: A photomicrograph of a rat testis of the control group showing PAS reaction of the basement membrane (black arrow) and in the acrosomal caps (blue arrows) of spermatids (PAS\&H. X200 and 1000).

Sections in the testis of the treated group (T1) showed focal disruption of the basement membrane of some tubules, while other tubules showed irregularity of the basement membrane and separation of it from the overlying germinal epithelium (Fig. 9).

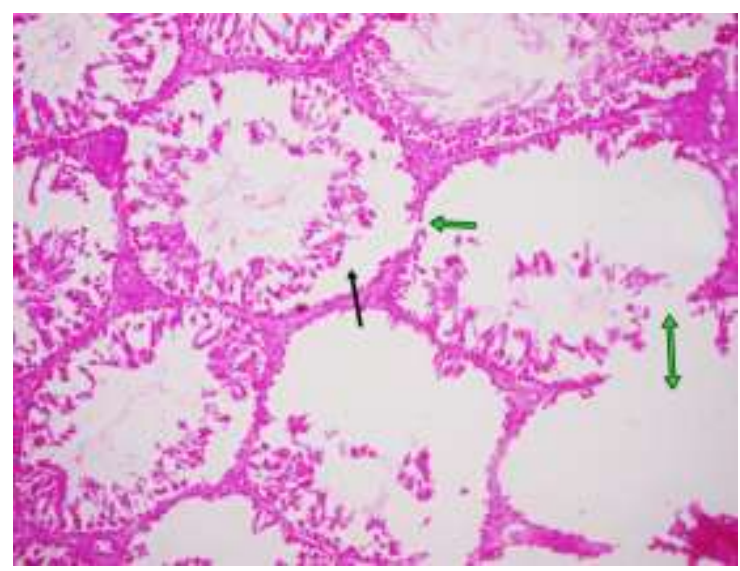

Fig.9: A photomicrograph of a section in the testis of the treated group (T1) showing focal disruption of the basement membrane of some tubules (green arrow) and wide separation between the basement membrane and germ cells (black arrow) (PAS \&H. X400).

Sections in the testis of the treated group (T2) showed less destruction from the previous group (T1) where there was a decline in the PAS reaction in the basal lamina of tubules. There was also irregularity and wrinkling of the basement membrane (Fig. 10). 


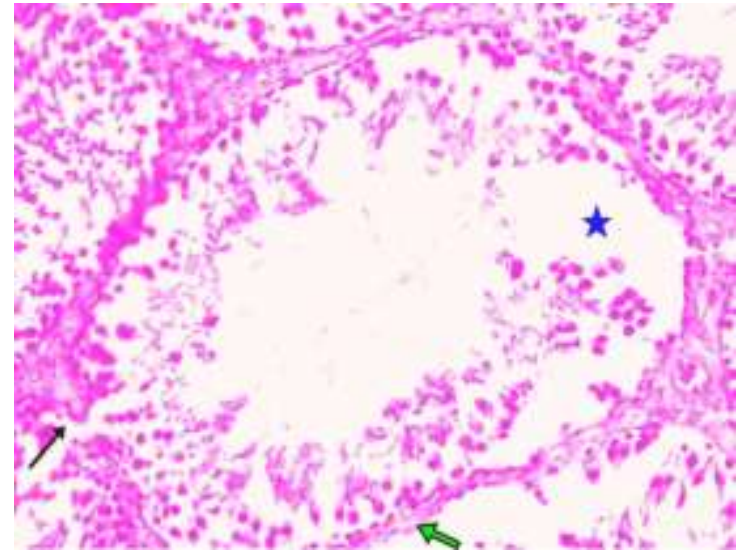

Fig.10: A photomicrograph of a section in the testis of the treated group (T2) showing focal disruption of the basement membrane of the seminiferous tubule (black arrow) and focal decrease of the PAS reaction in the irregular basement membrane of seminiferous tubule (green arrow). Loss of germ cells (blue star) (PAS \&H. $\mathrm{X} 400)$.

The group (R1a) showed mild improvement while the group (R1b) showed moderate improvement (Fig.11 and 12).

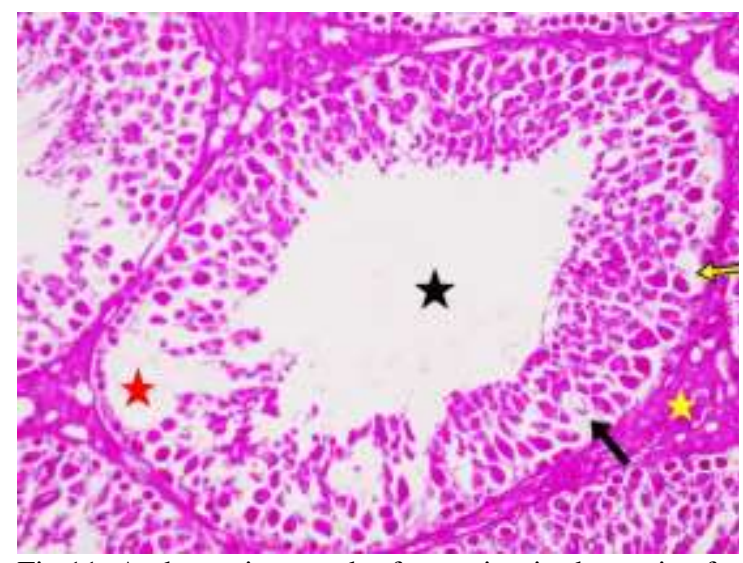

Fig.11: A photomicrograph of a section in the testis of the recovery group (R1a) showing cytoplasmic vacuolations of spermatogonia (yellow arrow) and Sertoli cell (black arrow). Focal loss of germ layers (red star), and absence of sperms and spermatids in the tubule (black star) (PAS\&H. X 400).

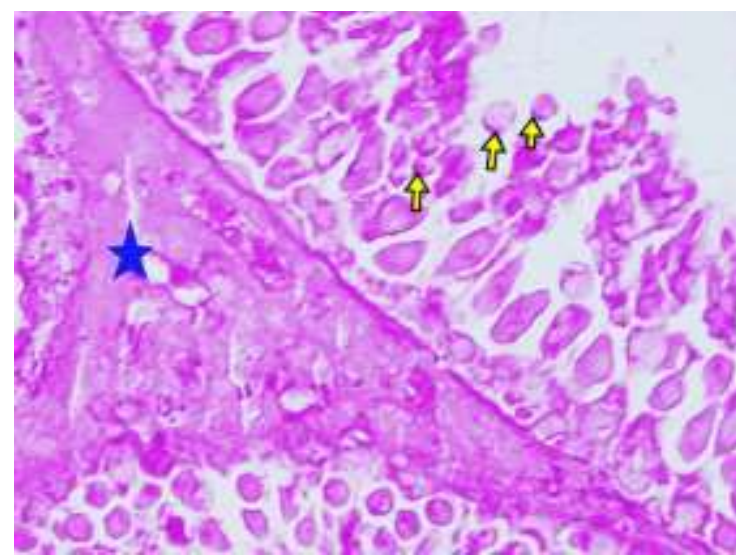

Fig.12: A photomicrograph of a section in the testis of the recovery group (R1b) showing vacuolated material (blue star) and strong PAS reaction in the acrosomal caps (yellow arrows) of spermatids in some tubules (PAS\&H. X 1000).

The group (R2a) showed moderate improvement while the group (R2b) showed marked improvement with apparently strong PAS-positive reaction in the basement membrane and acrosomal caps of spermatids in some tubules (Fig. 13 and 14).

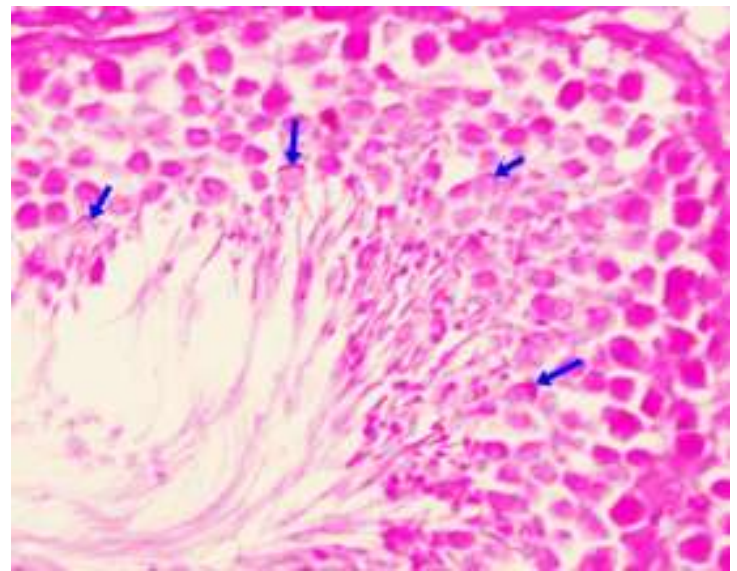

Fig.13: A photomicrograph of a section in the testis of the recovery group (R2a) showing moderate improvement of seminiferous tubule with PAS reaction in the acrosomal caps (blue arrows) (PAS \& H. X 1000).

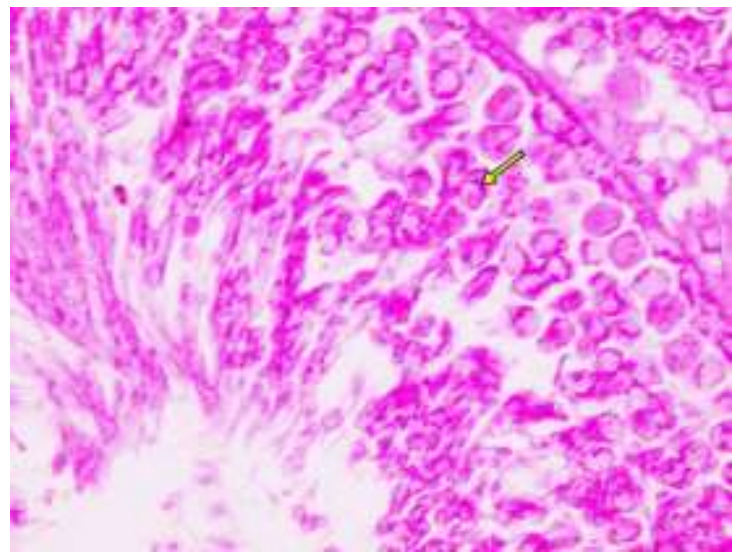

Fig.14: A photomicrograph of a section in the testis of the recovery group (R2b) showing seminiferous tubule with PAS reaction in the basement membrane and acrosomal caps (yellow arrow) (PAS\&H. X 1000).

Electron microscope examination of control animals showed that the seminiferous tubule was enclosed by a basal lamina and lined by spermatogenic epithelium following the normal series of spermatogonia, main spermatozoa, and spermatids. The primary spermatocytes appeared rounded above the spermatogonia, as large. Also, the early stage of spermiogenesis has been noted as the development of acrosomes and acrosomal cap in the seminiferous epithelium. The seminiferous tubules were essentially bound to Sertoli cells; their cytoplasm was abundant in mitochondria and lipid droplets, and the nucleus had a large nucleolus. Spermatogonia and sertoli cells living 
inside and interstitium on normal basement membrane with myoid cells within it (Fig. 15).

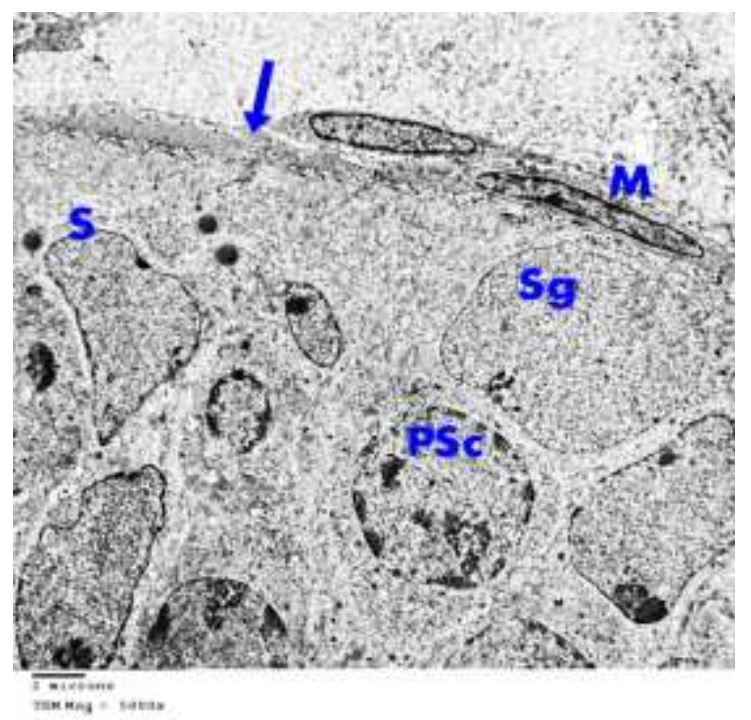

Fig.15: An electron photomicrograph of a section in the testis of the control group showing myoid cell (M) inside the basement membrane (blue arrow) of the tubule. Spermatogonia (Sg), primary spermatocyte (PSc), Sertoli cell (S) (TEM X5000).

In category (T1) the plurality of seminiferous tubules displayed important degenerative changes in the cell lineage of the seminiferous epithelium (Fig. 16).

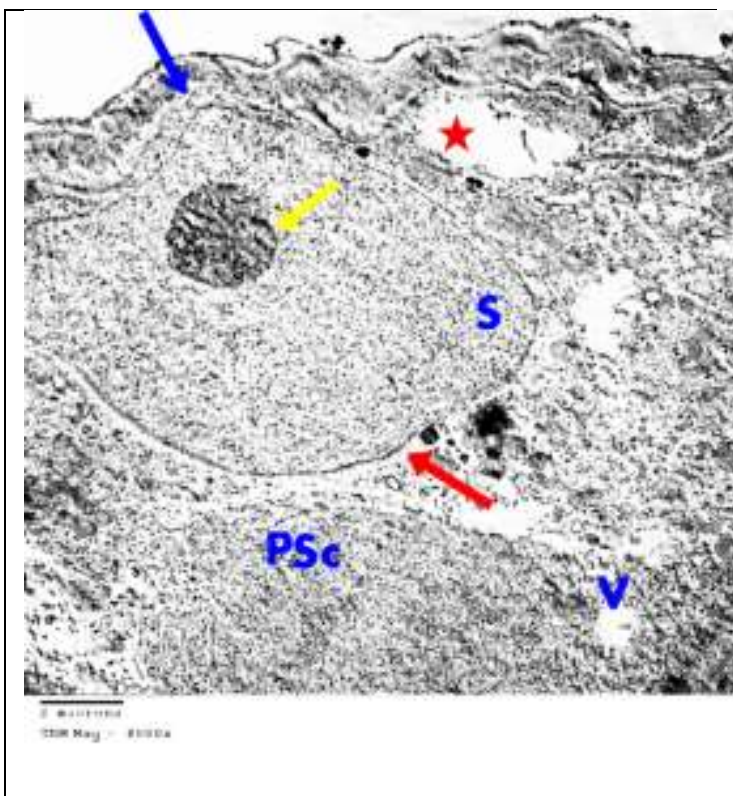

Fig.16: An electron photomicrograph of a section in the testis of the treated group (T1) showing Sertoli cell(S), primary spermatocyte (PSc), and large intracellular vacuoles (red star). Irregular basement membrane (blue arrow). vacuolation in the cytoplasm of spermatocyte (V), an irregular nucleus of Sertoli(red arrow), and large nucleolus (yellow arrow) (TEM X 2000).

Seminiferous tubules in the group (T2) showed less degenerative variations of the cell line of the seminiferous epithelium compared to the changes in the previous group (T1) (Fig. 17).

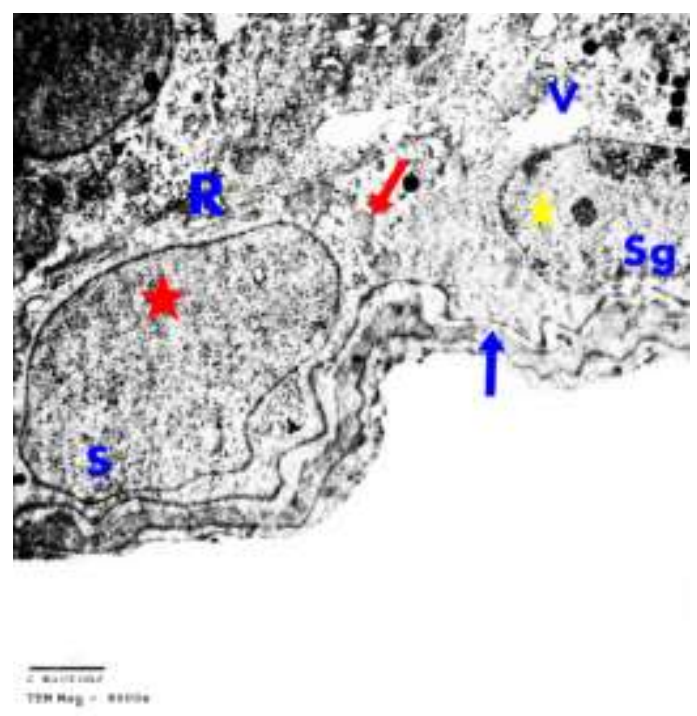

Fig.17: An electron photomicrograph of a section in the testis of the treated group (T2) showing Sertoli cell (S) with irregular nucleus (red star), its cytoplasm showing normal mitochondria (red arrow) and dilated RER (R). Spermatogonia $(\mathrm{Sg})$ shows large intracellular vacuoles in their cytoplasm (V). Sertoli cell and spermatogonia resting on irregular basement membrane (blue arrow) (TEM X 8000).

Some seminiferous tubules in the group (R1a) showed a mild improvement and marked improvement in the group (R1b) of the cell lineage of the seminiferous epithelium but many degenerative changes still present (Fig. 18 and 19).

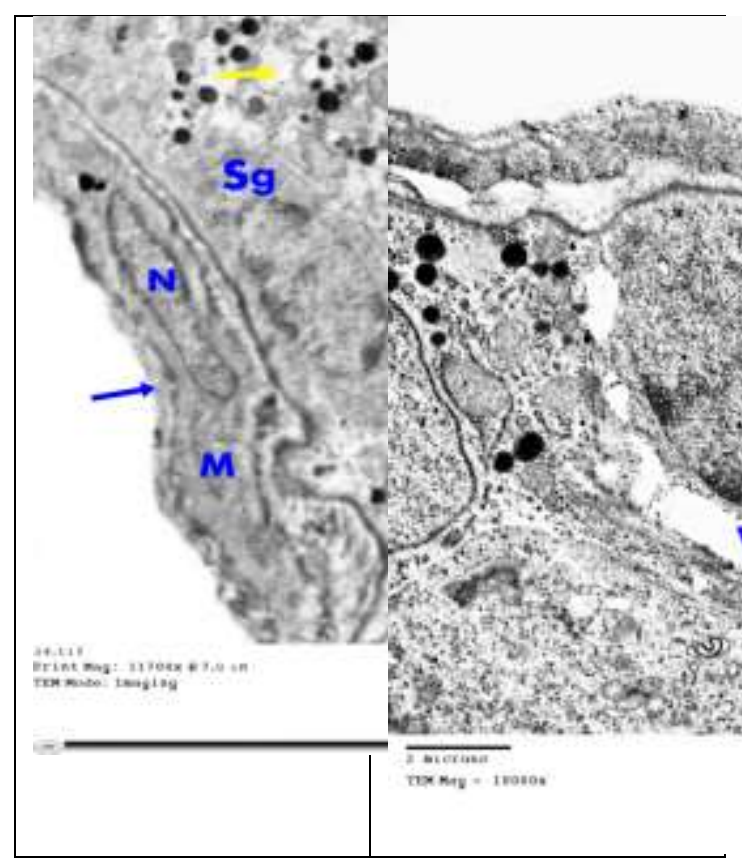

Fig.18: An electron photomicrograph of a section in the recovery group (R1a) showing Sertoli cell (S) with the intended irregular nucleus (green arrow). Spermatogonia (Sg), their cytoplasm have large 
vacuoles (V). Spermatogonia resting on irregular basement membrane (blue arrow) showing myoid cell (M) and its nucleus (N) inside it (TEM X 12000 and 10000).

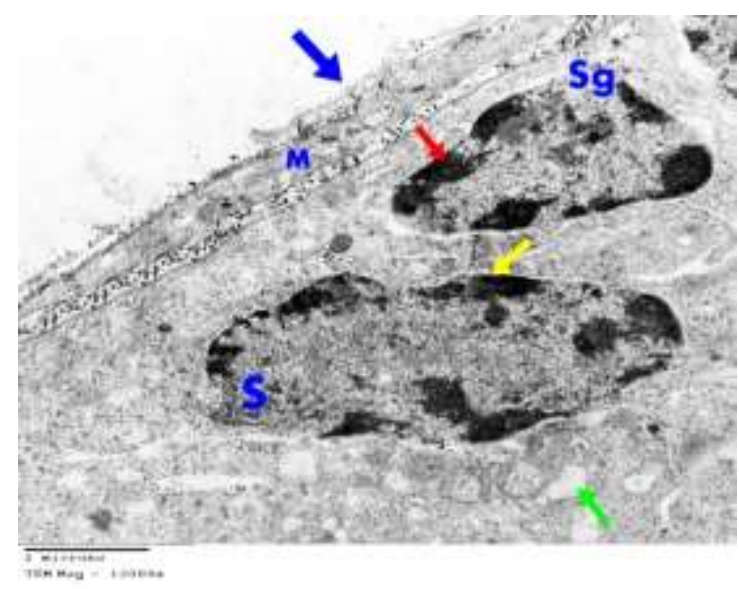

Fig.19: An electron photomicrograph of a section of the recovery group (R1b) showing spermatogonia $(\mathrm{Sg})$ resting on regular basement membrane (blue arrow) showing myoid cell (M) inside it with peripherally marginated heterochromatin (red arrow) Sertoli cell (S) with the nucleus and peripherally marginated heterochromatin (yellow arrow), their cytoplasm containing degenerated mitochondria (green arrow) (TEM X 12000).

Electron micrographs of the testis of the group (R2a) showed moderate improvement and marked improvement in the group (R2b) of spermatogonia and sertoli cells (Fig. 20 and 21).

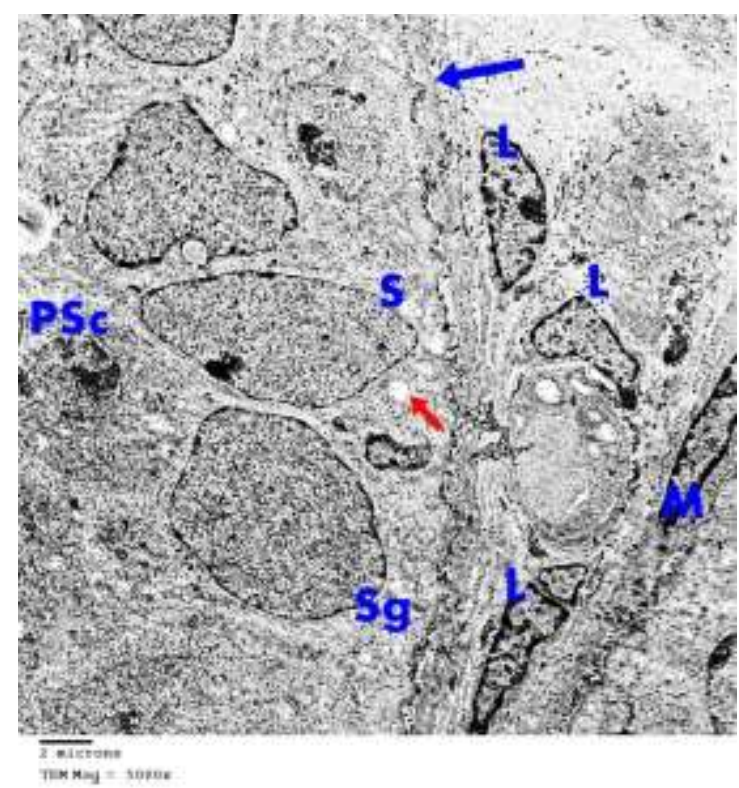

Anatomy

(Fig.20): An electron photomicrograph of a section of the recovery group (R2a) showing spermatogonia $(\mathrm{Sg})$ and Sertoli cell (S) with the nucleus, its cytoplasm containing degenerated mitochondria (red arrow). Primary spermatocyte (PSc). Spermatogonia and Sertoli cells resting on the basement membrane (blue arrow). Myoid cell (M). Cells of Ledyige (L) (TEM X 5000).

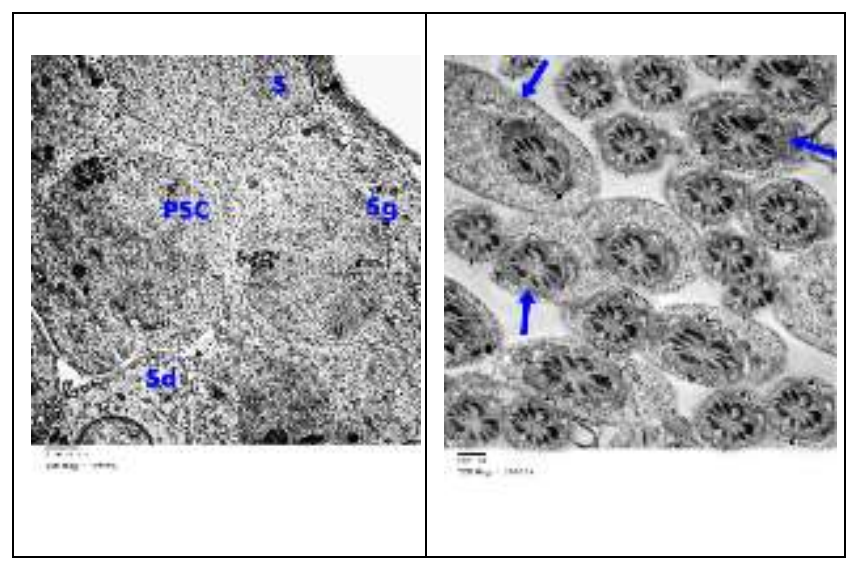

Fig. 21: An electron photomicrograph of a section of the recovery group ( $\mathrm{R} 2 \mathrm{~b})$ showing spermatogonia $(\mathrm{Sg})$, primary spermatocyte (PSc), Sertoli cell (S) with a large nucleus and round spermatid (Sd), with a round euchromatic nucleus. Increase in the number of sperms (blue arrow) in the lumen of seminiferous tubule (TEM x6000 and 20000).

Orcein stain: The elastic tissues within the scleral portion were markedly decreased from the $1^{\text {st }}$ to the $3^{\text {rd }}$ sacrifice and within all treated groups in a dose and time-dependent manner (Figure 9). 
Statistical results:

\begin{tabular}{|c|c|c|c|c|c|}
\hline \multirow{2}{*}{ Parameters } & Control & Treated 1 & Treated 2 & \multicolumn{2}{|c|}{ ANOVA } \\
\hline & Mean \pm SD & Mean \pm SD & Mean \pm SD & F-value & P-value \\
\hline Total volume of testes (mm3) & $418.2 \pm 24.6$ & $485.1 \pm 12.1$ & $463.3 \pm 10.8$ & 52.9 & $<0.01 *$ \\
\hline $\begin{array}{l}\text { Diameter of the seminiferous } \\
\text { tubules }(\mu \mathrm{m})\end{array}$ & $201.02 \pm 28.4$ & $111.93 \pm 22.1$ & $152.89 \pm 20.8$ & 50.9 & $<0.01 *$ \\
\hline Sperm count (million) & $\begin{array}{c}29.6 \times 105 \pm \\
21809233.52\end{array}$ & $\begin{array}{c}22.8 \times 105 \pm \\
16273458.53\end{array}$ & $\begin{array}{c}23.2 \times 105 \pm \\
15042458.43\end{array}$ & 50.1 & $<0.05^{*}$ \\
\hline No. of spermatogonia (million) & $63.15 \pm 8.15$ & $51.55 \pm 3.41$ & $59.50 \pm 6.54$ & 27.8 & $<0.05^{*}$ \\
\hline Interstitial tissue volume (mm3) & $64.3 \pm 12.4$ & $98.3 \pm 23.4$ & $91.5 \pm 35.9$ & 12.6 & $<0.07$ \\
\hline $\begin{array}{l}\text { Spermatogenic epithelium height } \\
(\mu \mathrm{m})\end{array}$ & $47.7 \pm 0.4$ & $41.6 \pm 8.1$ & $43.3 \pm 0.3$ & 18.7 & $<0.01 *$ \\
\hline No. of Leydig cells (million) & $15.4 \pm 0.6$ & $7.4 \pm 0.6$ & $12.8 \pm 1.4$ & 42.4 & $<0.02 *$ \\
\hline \multicolumn{6}{|c|}{ Tukey's test } \\
\hline C\&T1 & & \&T2 & & T1\&T2 & \\
\hline$<0.001 *$ & & $0.001 *$ & & $<0.001^{*}$ & \\
\hline
\end{tabular}

Table 1: Comparison of Mean Morphometric Parameters obtained from Testis of Control, Treated 1, and Treated 2 Groups.

Statistical analyses were carried out through one-way ANOVA, t-test and LSD tests, P-values $<0.05$ were considered as statistically significant, $\mathrm{C}=\mathrm{Control}$, Treated $1=$ group treated with $\mathrm{MSG}$, Treated $2=$ group treated with MSG+Ginger, $\mathrm{SD}=$ Standard deviation, and $*=$ Significant

ANOVAs and Tukey's tests were done to compare different groups of this study with the control group. The results obtained from the image analyzer, the subgroup (T2) revealed a significant increase in the total volume of testes when compared with the control group. The subgroup (T1) revealed a significant increase in the total volume of testes when compared with the control group and the subgroup (T2). Other measures as sperm count, numbers of spermatogonia, numbers of Leydig cells, Spermatogenic epithelium height, and diameter of the seminiferous tubules revealed a significant decrease in two subgroups (T1 and T2) when compared with the control group.

\begin{tabular}{|c|c|c|c|c|c|}
\hline \multirow{2}{*}{ Parameters } & T1 (10 Rats) & R1a (5 Rats) & R1b (5 Rats) & \multicolumn{2}{|c|}{ ANOVA } \\
\hline & Mean \pm SD & Mean \pm SD & Mean \pm SD & F-value & P-value \\
\hline Total volume (mm3) & $485.1 \pm 12.1$ & $449.5 \pm 9.1$ & $422.8 \pm 10.2$ & 32.6 & $<0.01^{*}$ \\
\hline $\begin{array}{l}\text { Diameter of the seminiferous } \\
\text { tubules }(\mu \mathrm{m})\end{array}$ & $111.93 \pm 22.1$ & $160.33 \pm 12.1$ & $190.89 \pm 23.8$ & 52.9 & $<0.01 *$ \\
\hline Sperm count(million) & $\begin{array}{c}22.8 \times 105 \pm \\
16273458.53\end{array}$ & $\begin{array}{c}25.6 \times 105 \pm \\
16872451.50\end{array}$ & $\begin{array}{c}26.1 \times 105 \pm \\
15947428.43\end{array}$ & 50.1 & $<0.05^{*}$ \\
\hline No of spermatogonia (million) & $51.55 \pm 3.41$ & $57.7 \pm 3.41$ & $59.53 \pm 6.54$ & 21.2 & $<0.05^{*}$ \\
\hline
\end{tabular}




\begin{tabular}{|c|c|c|c|c|c|}
\hline Interstitial tissue (mm3) & $98.3 \pm 23.4$ & $79.3 \pm 2.1$ & $70.5 \pm 4.1$ & 22.1 & $<0.06$ \\
\hline $\begin{array}{l}\text { Spermatogenic epithelium height } \\
(\mu \mathrm{m})\end{array}$ & $41.6 \pm 8.1$ & $42.9 \pm 3.1$ & $45.3 \pm 0.3$ & 19.9 & $<0.01 *$ \\
\hline No of Leydig cells (million) & $7.4 \pm 0.6$ & $8.5 \pm 0.4$ & $9.8 \pm 1.4$ & 32.4 & $<0.02 *$ \\
\hline \multicolumn{6}{|c|}{ Tukey's test } \\
\hline T1\& R1a & \multirow{2}{*}{\multicolumn{2}{|c|}{ T1 \& R1b }} & \multicolumn{3}{|c|}{ R1a \& R1b } \\
\hline$<0.005^{*}$ & & & \multicolumn{3}{|c|}{$<0.001^{*}$} \\
\hline
\end{tabular}

Table 2: Comparison of Mean Morphometric Parameters Obtained from Testis of first Treated Group (T1) and first Recovery Group (R1a and R1b) after stoppage administrations of Monosodium Glutamate For 6 and 13 Days Sequentially.

$\mathrm{T} 1=$ first Treated Group \& $\mathrm{R} 1 \mathrm{a}=6$ days after stoppage of monosodium glutamate and $\mathrm{R} 1 \mathrm{~b}=13$ days after stoppage monosodium glutamate.

ANOVAs and Tukey's tests were done to compare different groups of this study; the results obtained from the image analyzer, the subgroup (R1a) revealed a significant decrease total volume of testes when compared with the first treated group (T1). The subgroup (R1b) revealed a significant decrease total volume of testes when compared with the first treated group (T1) and the subgroup (R1a). Other measures as Sperm count, numbers of spermatogonia, numbers of Leydig cells, Spermatogenic epithelium height and diameter of the seminiferous tubules revealed a significant increase in subgroups (R1a) when compared with the first treated group (T1) also revealed a significant increase in subgroups (R1b) when compared with the first treated group (T1) and subgroups (R1a).

\begin{tabular}{|c|c|c|c|c|c|}
\hline \multirow{2}{*}{ Parameter } & T2 (10 Rats) & R2a (5 Rats) & R2b (5 Rats) & \multicolumn{2}{|c|}{ ANOVA } \\
\hline & Mean \pm SD & Mean \pm SD & Mean \pm SD & F-value & P-value \\
\hline Total volume (mm3) & $463.3 \pm 10.8$ & $435.1 \pm 12.1$ & $416.3 \pm 7.8$ & 4.9 & $<0.01 *$ \\
\hline $\begin{array}{l}\text { Diameter of the seminiferous } \\
\text { tubules }(\mu \mathrm{m})\end{array}$ & $152.89 \pm 20.8$ & $184.91 \pm 21.1$ & $197.29 \pm 28.8$ & 50.9 & $<0.01 *$ \\
\hline Sperm count & $\begin{array}{c}23.2 \times 105 \pm \\
15042458.43\end{array}$ & $\begin{array}{c}25.8 \times 105 \pm \\
16277458.93\end{array}$ & $\begin{array}{c}28.9 \times 105 \pm \\
15042958.75\end{array}$ & 5.1 & $<0.05^{*}$ \\
\hline No of spermatogonia (million) & $59.5 \pm 6.54$ & $60.8 \pm 3.41$ & $62.54 \pm 2.4$ & 20.1 & $<0.05^{*}$ \\
\hline Interstitial tissue (mm3) & $91.5 \pm 35.9$ & $76.3 \pm 23.4$ & $63.5 \pm 3.2$ & 10.9 & $<0.05^{*}$ \\
\hline $\begin{array}{l}\text { Spermatogenic epithelium height } \\
(\mu \mathrm{m})\end{array}$ & $43.3 \pm 0.3$ & $45.9 \pm 8.1$ & $47.3 \pm 0.3$ & 16.8 & $<0.01 *$ \\
\hline No of Leydig cells (million) & $12.8 \pm 1.4$ & $13.9 \pm 0.6$ & $14.4 \pm 0.6$ & 12.8 & $<0.02 *$ \\
\hline \multicolumn{6}{|c|}{ Tukey's test } \\
\hline T2 \& R2a & \multicolumn{2}{|c|}{$T 2 \& R 2 b$} & \multicolumn{3}{|c|}{ R2a \& R2b } \\
\hline$<0.001 *$ & \multicolumn{2}{|c|}{$<0.005^{*}$} & \multicolumn{3}{|c|}{$<0.005^{*}$} \\
\hline
\end{tabular}

Table 3: Comparison of Mean Morphometric Parameters Obtained from testis of the second Treated group (T2) and the second Recovery groups (R2a and R2b) after stoppage of Monosodium Glutamate and continuous administration of Ginger daily orally for 6 and 13 days.

$\mathrm{T} 2$ = group treated with MSG+Ginger for 14 days \& R2= Second Recovery Group \& R2a= group treated with MSG+Ginger for 14 days then followed by continuous treatment with ginger only for 6 days, and; $2 \mathrm{~b}=$ group treated with MSG+Ginger for 14 days then followed by continuous treatment with ginger only for 13 days. 
ANOVAs and Tukey's tests were done to compare different groups of this study; the results obtained from the image analyzer, the subgroup (R2a) revealed a significant decrease in the total volume of testes when compared with the second treated group (T2). The subgroup (R2b) revealed a significant decrease in the total volume of testes when compared with the second treated group (T2) and the subgroup (R2a). Other measures as Sperm count, numbers of spermatogonia, numbers of Leydig cells, Spermatogenic epithelium height and diameter of the seminiferous tubules revealed a significant increase in subgroups (R2a) when compared with the second treated group (T2) also revealed a significant increase in subgroups (R2b) when compared with the second treated group (T2) and subgroups (R2a).

\section{DISCUSSION}

In the current study, microscopic examination of (H\&E) stained sections from treated groups (T1\&T2) revealed histological changes in the testes caused by MSG, most of these changes were in accordance with ${ }^{12}$ who showed that MSG caused histological modifications in the tests of rats received MSG $4.0 \mathrm{~g} / \mathrm{kg}$ B.W orally, in the form of disorganized irregular tubules with the appearance of cytoplasmic vacuolation in most of the spermatogonia, with vacuolation in Sertoli cells compared to those of the control group.

This study indicated that MSG induced many histological and histomorphometric changes in the testicular tissue of rats. The changes include degeneration in seminiferous tubules epithelium with a reduction in sperm bundles. ${ }^{13}$

Short-term therapy with MSG showed mild to moderate disruption to seminiferous tubules in the shape of vacuoles within the spermatogonia cytoplasm and failure of late spermatogonia and long-term care induced serious harm to germ cells and the presence of large masses of necrotic cells in several tubes. ${ }^{14}$

These modifications may be attributed to either local or indirect consequences of gonadotrophic hormone imbalances. $^{15}$

In this study, homogenous acidophilic material or PASpositive material was observed in between the seminiferous tubules. This can be explained by interstitial edema. ${ }^{16}$

The results in an ultrastructural examination of sections obtained from treated groups (T1\&T2) are in agreement with. ${ }^{17}$

Results found in recovery groups were seen to be substantial incremental progress compared to study data collected from the groups permitted to heal after MSG therapy. ${ }^{18}$

The gradual increase in sperm count after the stoppage of MSG is due to a decrease in Leydig cells and steroid hormones. ${ }^{18}$

The gradual recovery of the testicular tissue which was observed in this work after stoppage of the intake of MSG may be due to relieve of oxidative stress caused by MSG with a gradual return of ascorbic acid to its normal level. ${ }^{19}$

The damage of testis done by MSG is reversible and may not result in irreversible damage, however, it will require a long time to restore the usual morphology of the testis.
Also, the present results were agreement with ${ }^{12}$ who reported that ginger improved, recovered, or prevented the histological and morphometric changes made by MSG in testes of rats that administered a combination of MSG and ginger, where the photomicrograph of testes of animals that received MSG and ginger showed no histological alterations, regular and well-organized tubules with normal interstitial connective tissue and Leydig cells.

Ginger overcame reproductive toxicity and induced spermatogenesis through the elevation of testosterone level. ${ }^{20}$

\section{CONCLUSION}

The damage of testis done by MSG is reversible and may not result in irreversible harm and infertility however the testis' regular morphology and histology will take a lengthy recovery period.

\section{REFERENCES}

1. Schrader S, Notara M, Beaconsfield M, Niaz K., Zaplatic E. and Spoor J. Extensive use of monosodium glutamate: A threat to public health?. EXCLI J. 2018; 17:273-278. doi:10.17179/excli2018-1092.

2. Alalwani AD. Monosodium glutamate-induced testicular lesions in rats (histological study). Production and hosting by Elsevier B.V. on behalf of the Middle East Fertility Society Journal. 2013; 09.003

3. Khalaf HA. and Arafat EA. Effect of different doses of monosodium glutamate on the thyroid follicular cells of adult male albino rats: a histological study. Int J Clin Exp Pathol 2015; 8(12):15498-15510.

4. Eweka AO., Igbigbi PS., and RE Ucheya. Histochemical Studies of the Effects of Monosodium Glutamate on the Liver of Adult Wistar Rats. Ann Med Health Sci Res. 2011 Jan-Jun; 1(1): 21-29.

5. Morakinyo AO., Adeniyi OS., and Arikawe AP. Effects of Zingiber Officinale on Reproductive Functions in the Male Rat. African Journal of Biomedical Research, 2008; vol. 11329 - 334.

6. Jalil H., Azar MM., Hani H., Mohammad ASGil., Farid D. and Mahdi S. The influence of ginger (Zingiber officinale) on human sperm quality and DNA fragmentation: A double-blind randomized clinical trial. Int J Reprod BioMed, August 2016; vol. 14. No. 8. pp: 533-540,

7. Onyema OO., Alisi CS., and Thetuge AP. Monosodium Glutamate Induces Oxidative Stress and Affects Glucose Metabolism in the Kidney of Rats. 
International Journal of Biochemistry Research\& Review, 2012 2(1): 1-11.

8. Memudu AE., Akinrinade ID., Ogundele OM. and Duru F. Effects of long and short-term treatment of aqueous extract of ginger (Zingibier Officinale) on male reproductive function of adult Sprague dawley rats. Journal of Medicine and Medical Science. 2012; 3(11): 692-696.

9. Ortiz G., Bitzer-Quintero O., Beas Zarate C., Rodri'guez- Reynoso C., Larios-Arceo F., Vela’ zquezBrizuela I., Pacheco- Moise's F. and Rosales-Corral S. Monosodium glutamate-induced damage in liver and kidney: a morphological and biochemical approach. Biomed Pharmacother, 2006 60(2): 86-91.

10. Wilson I. and Gamble M. The hematoxylins and eosins, In Theory, and practice of histological techniques, Bancroft JD and Gamble M (eds.), 5th ed., Churchill Livingston, Elsevier Science Limited, London, UK, pp. 125-138.

11. Hegazy R. and Hegazy A. Hegazy. Simplified Method of Tissue Processing (Consuming Less Time and Chemicals). Annals of International Medical and Dental Research, 2015; 1 (2), 57-61"

12. Mustafa SJ., Gulala IQ. and Shler AFM. Protective role of ginger on testicular tissue and testosterone hormone of male rats exposed to mono-sodium glutamate. jsmc, 2016; (vol 6) no. 2.

13. Das, R. and Ghosh, S. Long-term effects of monosodium glutamate on spermatogenesis following neonatal exposure in albino mice a histological study. Nepal. Med. Coll. J., 2010; 12(3):149-153.

14. Mohamed IK. The effects of oral dosage of monosodium glutamate (MSG) applied for short- and long-terms on the histology and ultrastructure of testes of the adult rats. J. Anim. Vet. Adv., 2010; 11(1):124133.

15. Ismail NH. Assessment of DNA Damage in Testes from Young Wistar Male Rat Treated with Monosodium Glutamate. Life Science Journal, 2012; 9(1): 930-939.

16. Creasy DM. Pathogenesis of Male Reproductive Toxicity. Huntingdon Life Sciences, 2001; 29 (1): 64 76.

17. Ihab KM. The effect of oral dosage of monosodium glutamate applied for short and long terms on the histology and ultrastructure of testes of the adult rats. Journal of animal and veterinary advances, 2012; 11(1): 124-133.

18. Nosseir NS., Ali MM., and Ebaid HM. A histological and morphometric study of monosodium glutamate toxic effect on testicular structure and potentiality of recovery in adult albino rat. Research Journal of Biology, 2012; 2(2): 66-78.

19. Vinodini NA., Nayanatara AK., Damodaragawda KM., Ahamad B. and Shabarinath S. Effect of monosodium glutamate-induced oxidative damage on rat testis. J. of Chinese Clinical Medicine, 2008; 3(7): 370-373.

20. Afshin Z., Fatemeh F., Arash K. and Behnam A. Protective Effect of Ginger on Gentamicin-Induced Apoptosis in Testis of Rats. Adv Pharm Bull. 2012; Dec; 2(2): 197-200.

21. Hegazy AA., Ibrahim IH., Sabry RM. and Abas ES. Effect of Gestational Exposure to Monosodium Glutamate on the Structure of Fetal Rat Lung. Anatomy Physiol Biochem Int J. 2017; 3 (2), 1-9. 